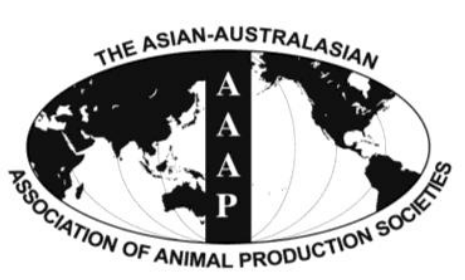

Open Access

Asian Australas. J. Anim. Sci. Vol. 27, No. 10 : 1394-1398 October 2014

http://dx.doi.org/10.5713/ajas.2014.14059

www.ajas.info

pISSN 1011-2367 elSSN 1976-5517

\title{
Native Pig and Chicken Breed Database: NPCDB
}

\author{
Hyeon-Soo Jeong, Dae-Won Kim ${ }^{1}$, Se-Yoon Chun ${ }^{1}$, Samsun Sung ${ }^{1}$, Hyeon-Jeong Kim ${ }^{1}$, \\ Seoae Cho ${ }^{1}$, Heebal Kim*, and Sung-Jong $\mathrm{Oh}^{2}{ }^{2} *$ \\ Interdisciplinary Program in Bioinformatics, Seoul National University, Seoul 151-742, Korea
}

\begin{abstract}
Indigenous (native) breeds of livestock have higher disease resistance and adaptation to the environment due to high genetic diversity. Even though their extinction rate is accelerated due to the increase of commercial breeds, natural disaster, and civil war, there is a lack of well-established databases for the native breeds. Thus, we constructed the native pig and chicken breed database (NPCDB) which integrates available information on the breeds from around the world. It is a nonprofit public database aimed to provide information on the genetic resources of indigenous pig and chicken breeds for their conservation. The NPCDB (http://npcdb.snu.ac.kr/) provides the phenotypic information and population size of each breed as well as its specific habitat. In addition, it provides information on the distribution of genetic resources across the country. The database will contribute to understanding of the breed's characteristics such as disease resistance and adaptation to environmental changes as well as the conservation of indigenous genetic resources. (Key Words: Indigenous (Native) Breeds, Database, Pig, Chicken, Conservation)
\end{abstract}

\section{INTRODUCTION}

Generally, livestock is used to describe any animal species that exist on earth with humans for a commercial and useful purpose. There are more than 40 species of livestock that have been domesticated during the last 10,000 to 12,000 years (Loftus and Scherf, 1993). The domestication of livestock animals has allowed for a settled lifestyle and has contributed as a source of food throughout the history (Hodges, 2003). It is also possible to obtain nonfood items such as wools, leather, fertilizer, and fuel. Also, livestock animals serve as a source of labor to support agricultural production and provide great help to economic development (Hall and Bradley, 1995). Globally, livestock contribute to about $4 \%$ to $5 \%$ of national economy and

\footnotetext{
* Corresponding Authors: Heebal Kim. Tel: +82-2-880-4822, Fax: +82-2-876-8827, E-mail: heebal@ snu.ac.kr / Sung-Jong Oh. Tel: +82-64-754-3335, Fax: +82-64-755-6130, E-mail: ohsj@jejunu.ac.kr

${ }^{1}$ C\&K Genomics, Seoul National University Research Park, Seoul 151-919, Korea.

${ }^{2}$ Department of Animal Biotechnology, Jeju National University, Jeju 690-756, Korea.

Submitted Jan. 23, 2014; Revised Apr. 1, 2014; Accepted May 1, 2014
}

supply some $30 \%$ of the total human requirements for food and agricultural production (Gandini and Oldenbroek, 1999).

In order to increase the economically important traits, domestic species have been improved through indiscriminate artificial insemination (Simm, 1998). For example, Holstein, a popular domesticated cattle breed, has been bred for milk production while domestic pig breeds have been bred for meat production. Some of these breeds, which are more economically productive, have spread many countries around the world (Giovambattista et al., 2001). As commercial breeds are dominated by large companies, they are quickly exported to different countries. Due to the introduction of commercial breeds, the ratio of indigenous breeds has gradually decreased in several regions of the world (Narrod and Fuglie, 2000). In some countries, when the number of native species is reduced by natural disasters or civil war, it is replaced by commercial breeds. This is one of the main causes for the reduction of genetic diversity (Giovambattista et al., 2001). Reduction of genetic resources generates serious problems. Due to the lack of interaction with other breeds and adaptation to the local environment for many years (Huxel, 1999), not all but the most of the indigenous breeds have relatively high genetic 
diversity and are resistance to disease (Baker, 1995). However, when domestic species are improved only for a particular trait, they may become vulnerable to epidemics, because of the loss of variants in the breed and disappearance of genes related to immunity. Due to these reasons, foot and mouth disease and avian influenza caused a devastating impact in the livestock industry (Yang et al., 1999; Alexander, 2000). Therefore, the conservation of diversity in the existing genetic resource is more important for economic and public health than for the development of new breeds with higher productivity (Moazami-Goudarzi et al., 1997; Keesing et al., 2006).

According to Food and Agriculture Organization (FAO), the level of extinction of native species that are held in each country is reaching a serious level. Of the 7,600 unique breeds listed by FAO, 20\% are designated as endangered, which includes pigs (18\%) and chicken $(33 \%)$ breeds. Also, the rate of extinction, currently at two breeds per week, is expected to accelerate. Moreover, in the developing countries, the situation is worse owing to a lack of information on the existing indigenous genetic resources (Ayalew et al., 2003). In order to conserve the diversity of livestock genetic resource, it is important to make a genetic resource conservation system with cooperation between genetic resource conservation centers, academia, breed associations, breed supply companies, and farms. To achieve this, efforts are required from a variety of institutions, but the construction of a database with accurate information on indigenous farm animal genetic resource would need to precede such a system. With the construction of a detailed information system of genetic resources including information on the population size, distribution, and phenotype, it is possible to grasp the status of the endangered native species and take measures to prevent extinction of the species (Dessie et al., 2009).

International organizations such as the International Livestock Research Institute (ILRI) and FAO have each made efforts to build a database on domestication farm animal genetic resources and as a result have created Domestic Animal Genetic Resources Information System (DAGRIS) and Domestic Animal Diversity Information System (DAD-IS), respectively (Ayalew et al., 2003; FAO 2001). One of the limitations of the currently available databases is that most of the information is not up to date. Moreover, the databases have an emphasis on cattle breeds, so there is a lack of integrated information about other domestication farm animals with accelerating rates of extinction.

Although indigenous pig and chicken breeds are important genetic resources and are currently under threat from extinction, there is no well-integrated information system on them. Thus, we developed the native pig and chicken breed database (NPCDB) in order to provide integrated information on indigenous pig and chicken breeds. Currently, information on these breeds are scattered and therefore, we collected data from different countries and integrated them. The NPCDB displays the population size of indigenous species in each country, their conservation status, and breed specific traits. Also, it provides statistical data on the accumulated information, so users can easily retrieve data on the indigenous pig and chicken breeds.

\section{MATERIALS AND METHODS}

\section{Database integration}

To provide integrated information on native pig and chicken breeds, we obtained 283 pig and 321 chicken breeds from a wide range of sources. The diversity information of each breed and its population size was obtained from DAD-IS (http://dad.fao.org/), DAGRIS (http://dagris.ilri.cgiar.org/browse.asp), and FAO-STAT (http://faostat3.fao.org/faostat-gateway/go/to/home/E). Phenotype feature and general information of indigenous genetic resources of each breed was obtained from the websites of the Department of Livestock in each country because there was a lack of a well-established database for the native breeds.

This database was developed using the programming language Python (http://www.python.org), and a MySQL (Structured Query Language; http://www.mysql.com) database was used for data storage and retrieval. For the efficient data processing and the function improvement of the user interface, the request is sent through Asynchronous JavaScript and XML (AJAX) to a custom-made hypertext processor (php) script.

\section{RESULTS}

\section{Overview of native pig and chicken breed database}

The NPCDB has been developed to provide information on the population size, distribution, and features of indigenous pig and chicken breeds. This is a noncommercial public database designed to support research, improvement of genetic resources, and conservation. The NPCDB, as an integrated information system, brings together information on indigenous pig and chicken breeds from many databases and available sources. It is a userfriendly database with a web-based interface allowing for easy access to a large amount of information. The aim of the database is to supply information to a variety of stakeholders including genetic resource conservation centers, academia, breed associations, breed supply companies, and farms on the special characteristics of the indigenous livestock. 


\section{Contents of native pig and chicken breed database}

This database displays the population size of the breeds in each country, their status of conservation, and phenotypic information. The interface of NPCDB consists of five main menus: 'Home', 'Native Pig', 'Native Chicken', 'Country', and 'Summary Statistics'. Users can easily obtain information about the indigenous pig and chicken breeds from the 'Native Pig' and 'Native Chicken' menus, while the 'Country' menu provides users with a quick overview of breed distribution and breed possession in each country. Summary information of species can be obtained from the 'Summary Statistics' menu (Figure 1). a

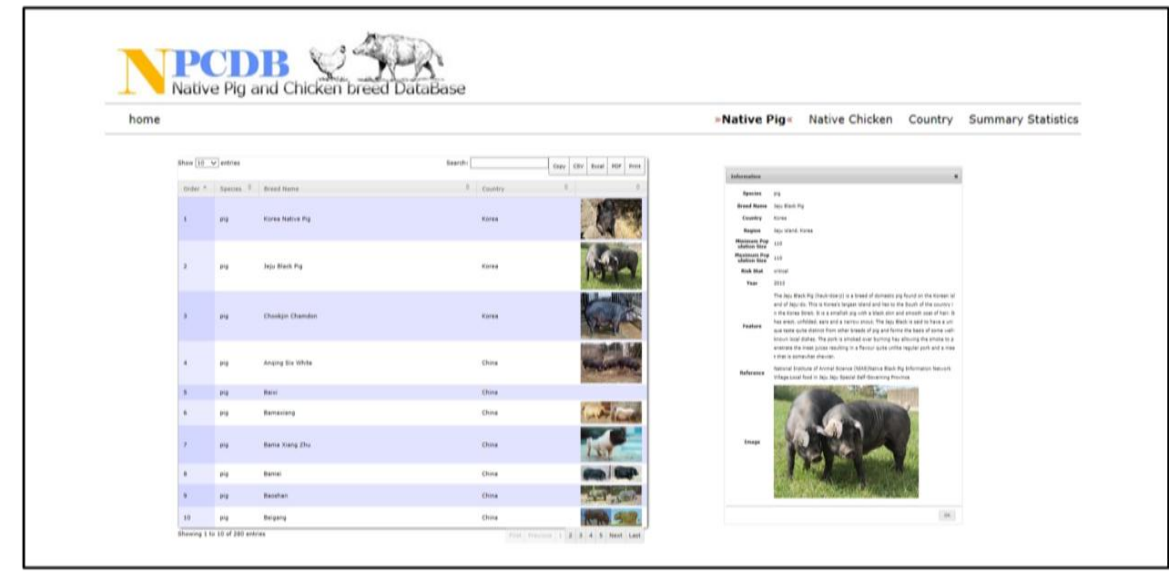

$\mathrm{b}$

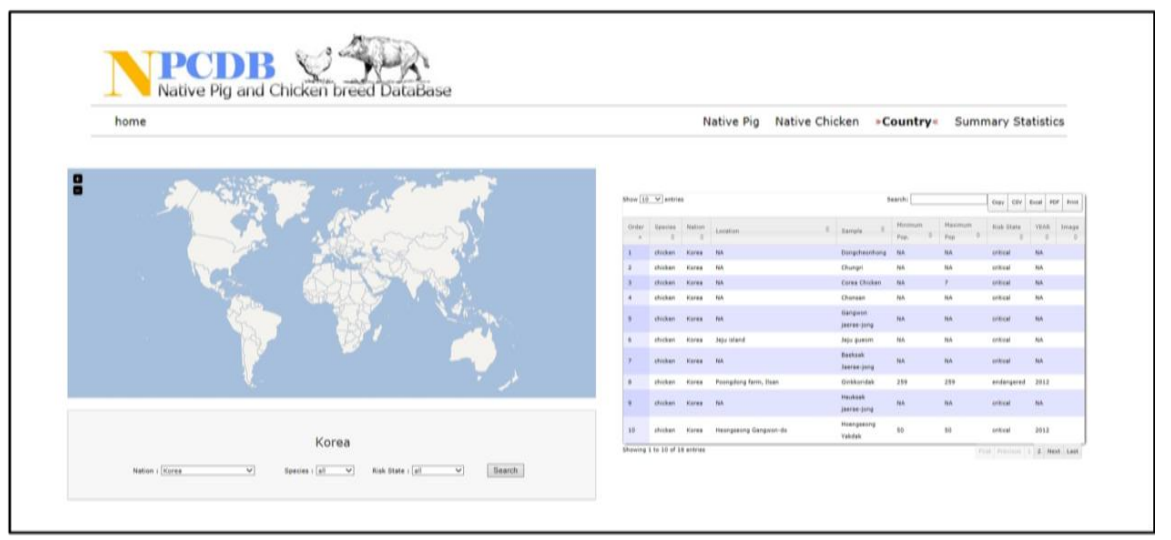

C

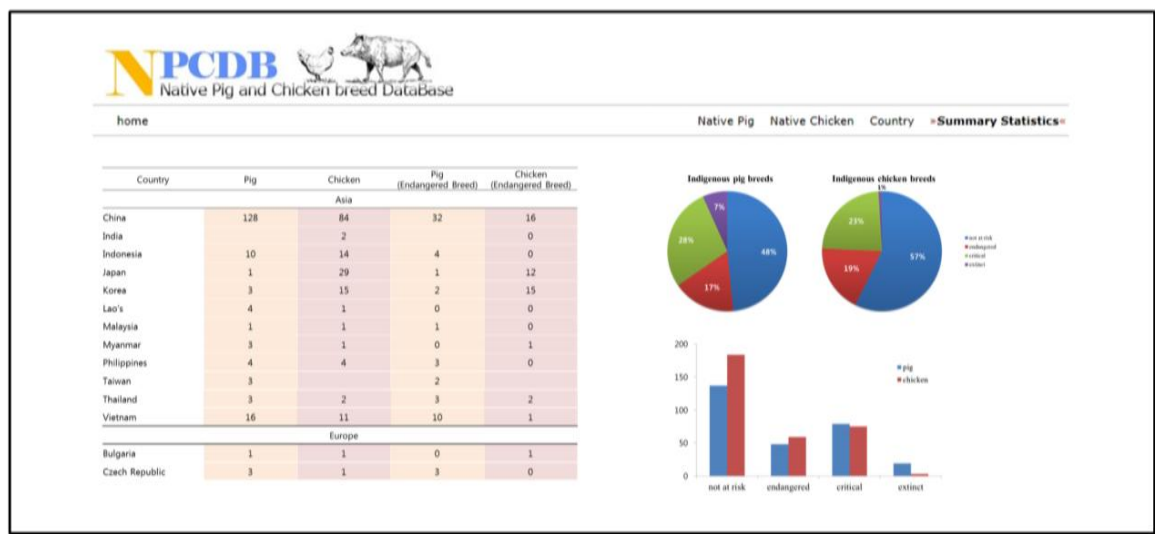

Figure 1. The webpage of native pig and chicken database (NPCDB). NPCDB is available at http://npcdb.snu.ac.kr/. This is a noncommercial public database designed to support research, improvement of genetic resources, and conservation. (a) The 'Native Pig' and 'Native Chicken' page provides information on the name of the breed, physical appearance, and its distribution. Detailed information of each breed is also available by clicking on the link. (b) The 'Country' page, users can be visualized the presence of indigenous breeds through the world map. When a user clicks on a specific country, information on the breeds and their pictures are provided. (c) The 'Summary Statistics' page offers summary information of the data through tables and figures. It has information about the accumulated data of what type of breed to country and continent giving the users an overview of all the data stored in NPCDB. 
The 'Native Pig' and 'Native Chicken' page provides information on the name of the breed and its distribution (Figure 1a). Physical appearance of each breed is provided through images of individuals of the breed. Detailed information of each breed is also available by clicking on the link. As the number of individuals is generally low for indigenous breeds and as they exist in a restricted area, the population size is important. Therefore, for each breed the population size information is provided.

On the 'Country' page, users can visualize the presence of indigenous breeds in each country through the world map (Figure 1b). When a user clicks on a specific country, information on the breeds and their pictures are provided. The most useful thing which can be found by using the menu is that it is able to recognize at a glance how the phenotype of the breed vary in each region, such as characteristics of the breed due to its geographical location. In terms of focusing on the origin of species, NPCDB currently only covers countries in Asia, Europe, Africa, Oceania and a few countries in South and North America. However, it is planned to expand the scope of countries by continuously adding new information. The 'Summary Statistics' page offers summary information of the data through tables and figures (Figure 1c). It has information about the accumulated data of the type of breed and its origin country giving the users an overview of all the data stored in NPCDB.

\section{DISCUSSION}

In this article, we described NPCDB, a web-based database which holds integrated information on indigenous pig and chicken breeds. The NPCDB provides comprehensive information on the genetic resources of indigenous pigs and chicken across the world. The NPCDB includes information on the population size, status, distribution and phenotype of each breed, and displays statistical information of the integrated data. The NPCDB is a public database made available free-of-charge. It is a useful database for various stakeholders that are interested in indigenous farm animal genetic resources. Especially as Southeast Asia and part of Africa rely heavily on pigs and chicken for food, preservation of genetic resources through a well-established database will have a large impact on the country's economy (Sugiyama et al., 2003). Currently, as the livestock genetic resource diversity is decreasing and the gravity of situation is becoming emphasized, the preservation of genetic resource diversity is becoming an important issue. Furthermore, once genetic resource goes extinct, its restoration is impossible so the accumulation of information to mitigate the loss is becoming increasingly important.

The NPCDB is not simply a database for preservation of genetic resources but an information source for a wide array of disciplines. Through this integrated database, phenotype information of indigenous genetic resources can be easily obtained. Also, the database can be used to investigate the different characteristics of the breeds by location. Finally, through comparisons of the characteristics of the indigenous species, information on disease resistance and environmental adaptation can be studied.

\section{ACKNOWLEDGMENTS}

This research was supported by a Grant from the Golden Seed Project (no.213005-04-1-WT111), Ministry of Agriculture, Food and Rural Affairs (MAFRA), Ministry of Oceans and Fisheries (MOF), Rural Development Administration (RDA) and Korea Forest Service (KFS), Republic of Korea.

\section{REFERENCES}

Alexander, D. J. 2000. A review of avian influenza in different bird species. Vet. Microbiol. 74:3-13.

Ayalew, W., J. E. O. Rege, E. Getahun, M. Tibbo, and Y. Mamo. 2003. Delivering systematic information on indigenous animal genetic resources - the development and prospects of DAGRIS. Proceedings of the Conference on Tropical and Subtropical Agricultural and Natural Resource Management (TROPENTAG), University of Gottingen, Deutschar. 8-10 October, 2003.

Baker, R. 1995. Genetics of disease resistance in small ruminants in Africa. ACIAR Monograph Serie 34:119-138.

Dessie, T., E. Getahun, Y. Mamo, J. Rege, O. Hanotte, and W. Ayalew. 2009. Delivering systematic information on indigenous farm animal genetic resources of developing countries: inclusion of poultry in DAGRIS. In: Village Chickens, Poverty Alleviation and the Sustainable Control of Newcastle Disease (Eds. R. G. Alders, P. B. Spradbrow, and M. P. Young). Proceedings of an international conference held in Dar es Salaam, Tanzania, 5-7 October, 2005. ACIAR Proceedings No. 131 p. 154-159.

FAO. 2001. Preparation of the first report on the state of the world's animal genetic resources. Guidelines for the Development of Country Reports. http://www.fao.org/dadis/ Accessed on October 1996.

Gandini, G. and J. Oldenbroek. 1999. Genebanks and the Management of Farm Animal Genetic Resource, DLO Institute for Animal Science and Health (Ed. J. K. Oldenbroek). Lelystad, The Netherlands. pp. 11-32.

Giovambattista, G., M. V. Ripoli, P. Peral-Garcia, and J. L. Bouzat. 2001. Indigenous domestic breeds as reservoirs of genetic diversity: the Argentinean Creole cattle. Anim. Genet. 32:240247.

Hall, S. J. and D. G. Bradley. 1995. Conserving livestock breed biodiversity. Trends Ecol. Evol. 10:267-270.

Hodges, J. 2003. Livestock, ethics, and quality of life. J. Anim. Sci. 81:2887-2894. 
Huxel, G. R. 1999. Rapid displacement of native species by invasive species: effects of hybridization. Biol. Conserv. 89:143-152.

Keesing, F., R. D. Holt, and R. S. Ostfeld. 2006. Effects of species diversity on disease risk. Ecol. Lett. 9:485-498.

Loftus, R. and B. Scherf. 1993. World watch list for domestic animal diversity. FAO, United Nations, Rome.

Moazami-Goudarzi, K., J. Furet, F. Grosclaude, and D. Laloë. 1997. Analysis of genetic relationships between 10 cattle breeds with 17 microsatellites. Anim. Genet. 28:338-345.
Narrod, C. A. and K. O. Fuglie. 2000. Private investment in livestock breeding with implications for public research policy. Agribusiness 16:457-470.

Simm, G. 1998. Genetic Improvement of Cattle and Sheep. Farming Press, Wallingford, UK.

Sugiyama, M., A. Iddamalgoda, K. Oguri, and N. Kamiya. 2003. Development of livestock sector in Asia: an analysis of present situation of livestock sector and its importance for future development. Gifu City Women's College, Gifu, Japan 52.

Yang, P. C., R. M. Chu, W. B. Chung, and H. T. Sung. 1999. Epidemiological characteristics and financial costs of the 1997 foot-and-mouth disease epidemic in Taiwan. Vet. Rec. 145:731-734. 